\title{
A survey among physicians in surgery and anesthesiology departments after the first surge of SARS-CoV-2 infections in Germany
}

\author{
Preparing for further challenges ahead
}

\begin{abstract}
Anna Grishina - Fabian Link · Arne Arend · Florentine Kleemann · Pinkus Tober-Lau • Dominik Andree • Friederike Münn · Magdalena Gruendl · Markus Quante · Hans Lederhuber · Markus Albertsmeier · Florian Struller · Robert Grützmann · Alfred Königsrainer · Markus W. Löffler $\mathbb{D}$
\end{abstract}

Received: 9 July 2021 / Accepted: 21 December 2021 / Published online: 21 January 2022

(C) The Author(s) 2022

\section{Summary \\ Background The SARS-CoV-2 pandemic has exten- sively challenged healthcare systems all over the world. Many elective operations were postponed or cancelled, changing priorities and workflows in surgery departments.}

\section{A. Grishina}

Department of Pediatrics I, University Medicine Essen,

University of Duisburg-Essen, Essen, Germany

F. Link

University Hospital Halle (Saale), Halle, Germany

\section{A. Arend}

Martin-Luther-University Halle (Saale), Halle, Germany

F. Kleemann

Medical Faculty, Greifswald University Hospital, Greifswald,

Germany

\section{P. Tober-Lau · F. Münn}

Department of Infectious Diseases and Respiratory

Medicine, Charité-Universitätsmedizin Berlin, Berlin,

Germany

\section{Andree}

Faculty of Arts and Social Sciences, Open University, Milton Keynes, UK

\section{Gruendl}

Department of Sport and Health Sciences, Chair of Epidemiology, Technical University Munich, Munich, Germany

M. Quante · A. Königsrainer · M. W. Löffler $(\bowtie)$ Department of General, Visceral and Transplant Surgery, University Hospital Tübingen,

Hoppe-Seyler-Str. 3, 72076 Tübingen, Germany

Markus.Loeffler@med.uni-tuebingen.de
Aims The primary aim of this cross-sectional study was to assess the workload and psychosocial burden of surgeons and anesthesiologists, working in German hospitals during the first wave of SARS-CoV-2 infections in 2020.

H. Lederhuber

Department of Colorectal Surgery, Royal Devon and Exeter NHS Foundation Trust, Exeter, UK

\section{Albertsmeier}

Department of General, Visceral and

Transplantation Surgery, LMU University Hospital,

Ludwig-Maximilians-University (LMU) Munich, Munich,

Germany

F. Struller $\cdot$ R. Grützmann

Department of Surgery, University Hospital Erlangen, Erlangen, Germany

A. Königsrainer · M. W. Löffler

Cluster of Excellence iFIT (EXC2180) "Image-Guided and Functionally Instructed Tumor Therapies”, University of Tübingen, Tübingen, Germany

\section{W. Löffler}

Department of Immunology, Interfaculty Institute for Cell Biology, University of Tübingen, Tübingen, Germany

Department of Clinical Pharmacology, University Hospital Tübingen, Tübingen, Germany 
Methods Quantitative online survey on the workplace situation including psychosocial and work-related stress factors among resident and board-certified surgeons and anesthesiologists. Physicians in German hospitals across all levels of healthcare were contacted via departments, professional associations and social media posts.

Results Among 154 total study participants, 54\% of respondents stated a lack of personal protective equipment in their own wards and 56\% reported increased staff shortages since the onset of the pandemic. While routine practice was reported as fully resumed in $71 \%$ of surgery departments at the time of the survey, work-related dissatisfaction among responding surgeons and anesthesiologists increased from $24 \%$ before the pandemic to $36 \%$ after the first wave of infections. As a countermeasure, $94 \%$ of participants deemed the establishment of action plans to increase pandemic preparedness and strengthening German public health systems a useful measure to respond to current challenges.

Conclusion The aftermath of the first wave of SARSCoV-2 infections in Germany has left the surgical staff strained, despite temporarily decreased workloads. Overall, a critical review of the altered conditions is indispensable to identify and promote effective solutions and prudent action plans required to address imminent challenges.

Keywords COVID-19 - Healthcare - Stress factors · Working conditions · Work-related dissatisfaction

\section{Introduction}

The ongoing severe acute respiratory syndrome coronavirus type 2 (SARS-CoV-2) pandemic has directly impacted the situation of healthcare professionals and has caused alarming effects on a global scale [1-3]. In addition to high workloads and limited resources, healthcare professionals are now facing various unprecedented challenges. Besides a relevantly increased risk of becoming infected and falling ill themselves [4-6], the pandemic has also had a considerable impact on the workload of healthcare providers [7-9]. In particular, the daily routines in surgical departments have massively changed during the pandemic. Since patients contracting SARSCoV-2 during or after a surgical intervention are at risk of developing severe perioperative complications and have high mortality rates [10], elective surgical procedures were postponed or cancelled in many hospitals, intending to protect patients [10-12]. Such measures also aimed at preserving sufficient capacities for critically ill coronavirus disease 2019 (COVID-19) patients at intensive care units. As a result, numerous surgical procedures that have been postponed will have to be performed between COVID-19 waves or later on [13]. After infection surges, this will likely result in increasing workloads for surgical departments without the possibility of compensating these challenges by additional staff [14].

The primary objective of this study was therefore to assess the changes regarding workload and psychosocial burden for surgeons and anesthesiologists in the aftermath of the first wave of SARS-CoV-2 infections in Germany. In addition, the survey assessed participants' resilience and mitigation strategies with a focus on potential solutions for future surges and challenges, referring to the general health system level in Germany.

\section{Material and methods}

A self-developed web-based questionnaire was created using the online survey platform LimeSurvey (LimeSurvey GmbH, Hamburg, Germany; https:// www.limesurvey.org). Invitations to participate in the survey with an access link were sent by mail to the official contacts of surgery and anesthesiology departments in over 300 hospitals across all healthcare levels in Germany with a request to forward them to respective department members, as well as communicated through professional associations and posts on social media channels. The questionnaire was created exclusively for this study. Survey participation was possible from 19 July until 30 September 2020. Participants were physicians working across all surgical disciplines (including e.g., general surgery, ophthalmology and gynecology) or anesthesiology departments in German hospitals (employed since 1 January 2020 or before). Participants were contacted through their institutional email and by means of different associations, thus a concrete sample size regarding persons inquired for survey participation cannot be provided. Participants responding to the questionnaire gave their consent before starting the survey, including the use of their anonymized data. The study protocol was reviewed by the local Ethics Committee at the University of Tübingen and a positive vote was obtained (project number: 513/2020BO). The survey consisted of 49 questions (in German). One section of the survey collected demographic data (including sex, age, ethnicity, marital status, etc.), another addressed working conditions and workload before the pandemic and own health-related risk factors as well as information on continuation of elective surgical procedures. The last section of the survey focused on the identification of psychosocial stress factors due to the SARS-CoV-2 pandemic, covering both the personal as well as work-related settings (Fig. 1). The questionnaire comprised a mixture of question styles, including dichotomous questions (yes/no questions), single selection questions, multiple choice questions and Likert-type scale items (including answer formats such as: strongly agree/agree/neither agree nor disagree/disagree/strongly disagree).

To assess the workload, work-related satisfaction as well as occupational exhaustion before and during 


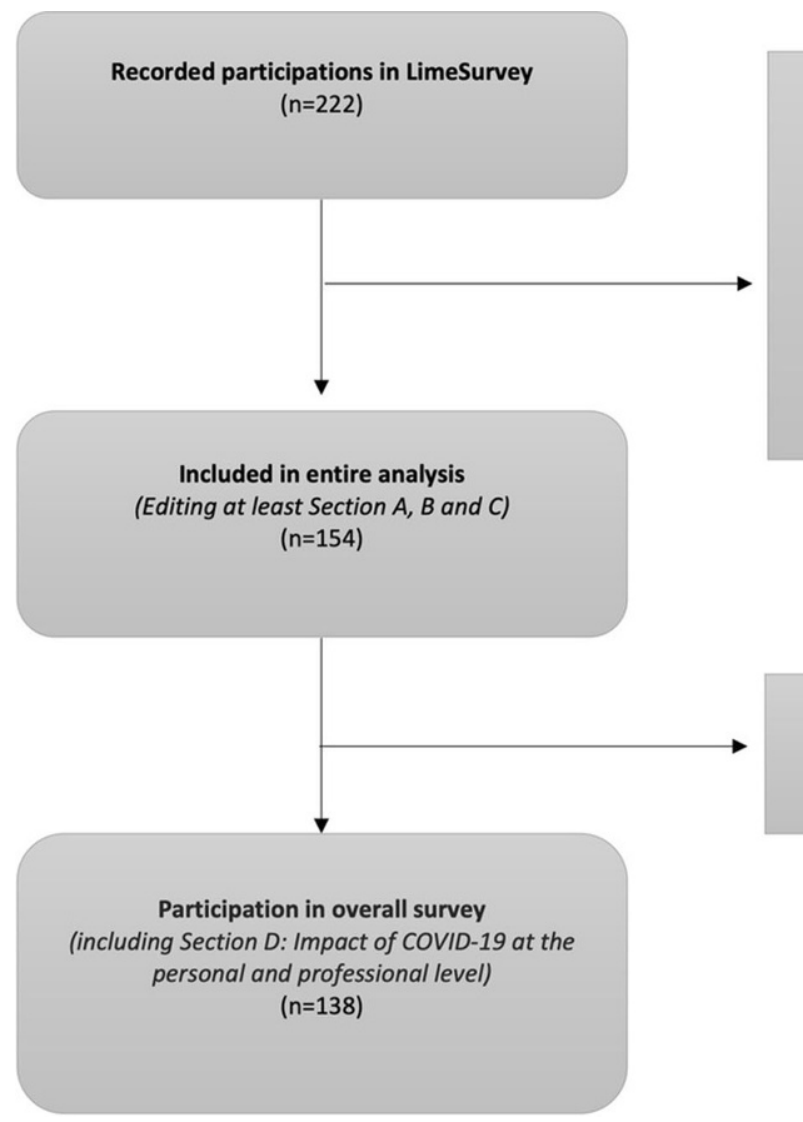

Fig. 1 Flow chart of study participants. The flow chart depicts the participation in the different survey sections via the LimeSurvey platform with respective numbers $(n)$. Since sev-

the SARS-CoV-2 pandemic, two different time frames in consecutive order with structurally identical items were provided. Questions on subjective perceptions, addressing aspects such as workload or job satisfaction before and during the SARS-CoV-2 pandemic were assessed as consecutive questions using 5-point Likert-type scale items with the additional answer option "No answer", ranging from "Strongly disagree" to "Strongly agree". Using a 11-item section of the questionnaire, the first six items inquired to what extent the respondents agreed or disagreed with statements concerning their personal workload, work satisfaction and occupational exhaustion (Fig. 2). In the following, several examples for the phrasing of typical questions are provided, as translated by the authors from the German original. A first block of questions was used to evaluate the situation in retrospect (e.g.: "Before the onset of the COVID-19 pandemic, my workload was high", "Before the onset of the COVID-19 pandemic, I felt overwhelmed at work" or "Before the onset of the COVID-19 pandemic, I often felt dissatisfied at work"). Subsequently, to evaluate the current situation statements like "Currently my workload is high", "Currently I feel overwhelmed at work" or "Currently, I often feel dissatisfied at work" were inquired in a second block of questions belonging to the same set of items. To
Excluded $(n=68)$

- Survey discontinued after informed consent $(n=38)$

- Drop-out after Section A: Creation of personal code $(n=10)$

- Drop-out after Section B: Demographics $(n=20)$
Drop-out after Section C: Working conditions and workloads $(n=16)$ eral participants dropped out, the number $(n)$ of participants in each section is presented, alongside the drop-out rates by section. Overall, 138 people completed the entire survey

evaluate which factors influence work-related dissatisfaction, the participants were asked to what extent several stress factors changed during the pandemic, on a 5-point Likert scale ranging from "Strongly decreased" to "Strongly increased" complemented by the two further answer options "Not applicable" and "No answer". An exemplary item for this category of questions is "Acquisition of new knowledge and skills within a short time has ..." (Fig. 3).

\section{Statistical analysis}

Data was analyzed using IBM SPSS Statistics version 26.0 (IBM Corp., Armonk, NY, USA). Data are presented as total numbers $(n)$ and means. To estimate the statistical association between different questions on the questionnaire, Spearman's rank correlation coefficient was used. To prevent the accumulation of alpha errors, a Bonferroni correction was performed. We assumed $p<0.05$ to indicate statistically significant differences. 


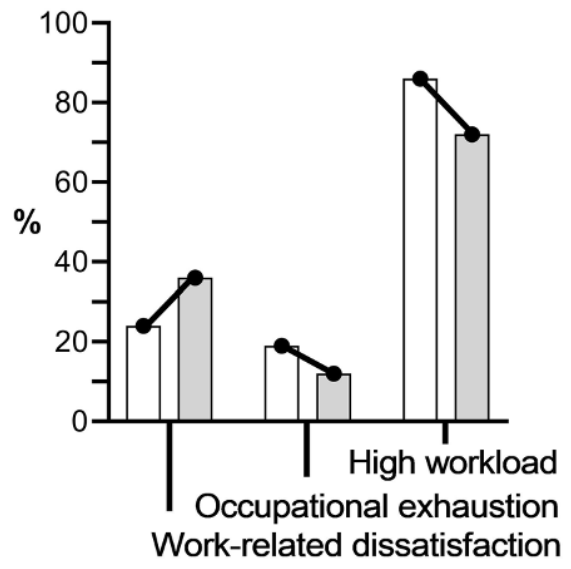

Fig. 2 Changes in working conditions comparing the situation before and during the pandemic. The bar chart depicts \% changes in work-related aspects before and during the pandemic (after the first wave of SARS-CoV-2 infections in Germany) as reported by survey participants $(n=138)$. The items presented are shortened statements from original questions. An exemplary pair of items (as authors' translation from German) used is "Before the onset of the COVID-19 pandemic, my workload was high" and "Currently, my workload is high"

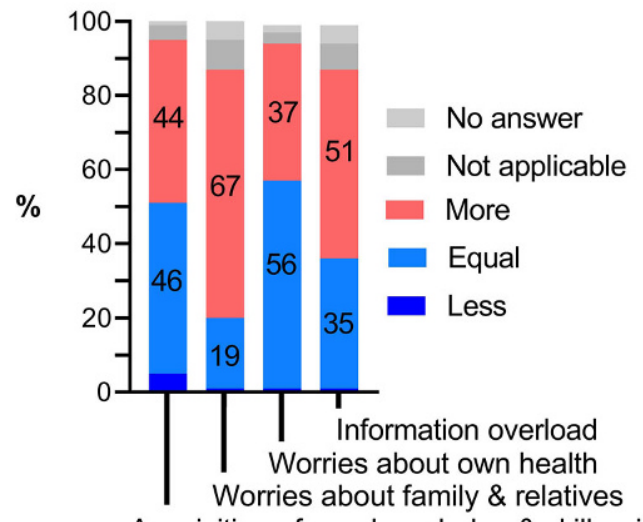

Acquisition of new knowledge \& skills within short time

Fig. 3 Work-related stress factors perceived by study participants. The bar graph illustrates \% fractions of selected workrelated stress factors during the SARS-CoV-2 as increased (more), equal or less, when compared to the situation before the pandemic by survey participants $(n=138)$

\section{Results}

\section{Demographics}

Among 222 started surveys recorded in LimeSurvey, 154 participants completed the survey at least in parts and were included in the analysis. Sixty-eight survey responses were excluded from the analysis due to discontinuation before completing the relevant sections B and C. In total, 138/154 participants (90\%) completed the full survey (Fig. 1). From the full study cohort 58/154 participants (38\%) indicated to be females and $94 / 154(61 \%)$ to be males (in two cases data were lacking). Age distribution is shown in Table 1 . Out of the 154 anesthesiologists and surgeons,
Table 1 Study participant characterization $(n=154)$ and hospital information

\begin{tabular}{|c|c|c|c|}
\hline & $n$ & $\%$ \\
\hline \\
\hline \multicolumn{2}{|l|}{ Female } & 58 & 38 \\
\hline \multicolumn{2}{|l|}{ Male } & 94 & 61 \\
\hline \multicolumn{2}{|l|}{ No answer } & 2 & 1 \\
\hline \multicolumn{4}{|l|}{ Age (years) } \\
\hline \multicolumn{2}{|l|}{ 25-34 } & 54 & 35 \\
\hline \multicolumn{2}{|l|}{$35-44$} & 35 & 23 \\
\hline \multicolumn{2}{|l|}{$45-54$} & 40 & 26 \\
\hline \multicolumn{2}{|l|}{$55-64$} & 23 & 15 \\
\hline \multicolumn{2}{|l|}{$\geq 65$} & 1 & $<1$ \\
\hline \multicolumn{2}{|l|}{ No answer } & 1 & $<1$ \\
\hline \multicolumn{4}{|l|}{ Professional status } \\
\hline \multicolumn{2}{|l|}{ Resident } & 54 & 35 \\
\hline \multicolumn{2}{|c|}{ Specialist physician (board certified) } & 20 & 13 \\
\hline \multicolumn{2}{|c|}{ Consultant (senior physician) } & 37 & 24 \\
\hline \multicolumn{2}{|c|}{ Chief physician (head of department) } & 40 & 26 \\
\hline \multicolumn{2}{|c|}{ No answer } & 3 & 2 \\
\hline \multicolumn{4}{|l|}{ Hospital category } \\
\hline \multirow[t]{2}{*}{ First-level hospital care } & Basic provider hospital & 18 & 12 \\
\hline & Outpatient surgery center & 1 & $<1$ \\
\hline Second-level hospital care & Focus provider hospital & 46 & 30 \\
\hline \multirow[t]{2}{*}{ Third-level hospital care } & Maximum care hospital & 21 & 14 \\
\hline & University hospital & 67 & 43 \\
\hline \multicolumn{2}{|l|}{ No answer } & 1 & $<1$ \\
\hline \multicolumn{4}{|l|}{ Location of hospitals } \\
\hline \multicolumn{2}{|l|}{ North Rhine-Westphalia } & 35 & 23 \\
\hline \multicolumn{2}{|l|}{ Baden-Württemberg } & 32 & 21 \\
\hline \multicolumn{2}{|l|}{ Bavaria } & 20 & 13 \\
\hline Lower Saxony & & 15 & 10 \\
\hline Hesse & & 10 & 7 \\
\hline Saxony & & 7 & 5 \\
\hline Berlin & & 6 & 4 \\
\hline Rhineland-Palatinate & & 5 & 3 \\
\hline Saxony-Anhalt & & 5 & 3 \\
\hline Schleswig-Holstein & & 5 & 3 \\
\hline Thuringia & & 4 & 3 \\
\hline Brandenburg & & 3 & 2 \\
\hline Bremen & & 2 & 1 \\
\hline Hamburg & & 2 & 1 \\
\hline Saarland & & 2 & 1 \\
\hline No answer & & 1 & $<1$ \\
\hline
\end{tabular}

54 identified as residents (35\%) and 97 as board-certified physicians $(63 \%$, in three cases data were lacking). Thereof, $40 / 97(41 \%)$ stated that they work as a head of department (Table 1). Respondents were from hospitals all over Germany, including all levels of healthcare, with a predominant share from maximum care and university hospitals (57\%). Further information, including data related to levels of hospital care and location, is provided in Table 1 . The subdivision of 
Table 2 Classification of study participants by specialization and level of professional education $(n=154)$

\begin{tabular}{|c|c|c|}
\hline Specialization & $n$ & $\%$ \\
\hline \multicolumn{3}{|l|}{ Residents $(n=54)$} \\
\hline General surgery & 4 & 7 \\
\hline Anesthesiology & 15 & 28 \\
\hline Ophthalmology & 2 & 4 \\
\hline Dermatology & 1 & 2 \\
\hline Vascular surgery & 1 & 2 \\
\hline Gynecology & 1 & 2 \\
\hline Otorhinolaryngology & 2 & 4 \\
\hline Pediatric surgery & 1 & 2 \\
\hline Oral and maxillofacial surgery & 2 & 4 \\
\hline Neurosurgery & 1 & 2 \\
\hline Orthopedics and trauma surgery & 2 & 4 \\
\hline Plastic and aesthetic surgery & 2 & 4 \\
\hline Urology & 2 & 4 \\
\hline Visceral surgery & 18 & 33 \\
\hline \multicolumn{3}{|l|}{ Board-certified physicians $(n=97)$} \\
\hline General surgery & 21 & 22 \\
\hline Anesthesiology & 28 & 29 \\
\hline Ophthalmology & 3 & 3 \\
\hline Dermatology & 1 & 1 \\
\hline Vascular surgery & 5 & 5 \\
\hline Gynecology & 4 & 4 \\
\hline Otorhinolaryngology & 3 & 3 \\
\hline Cardiac surgery & 1 & 1 \\
\hline Oral and maxillofacial surgery & 2 & 2 \\
\hline Neurosurgery & 3 & 3 \\
\hline Orthopedics and trauma surgery & 8 & 8 \\
\hline Thoracic surgery & 5 & 5 \\
\hline Urology & 2 & 2 \\
\hline Visceral surgery & 11 & 11 \\
\hline Unknown $(n=3)$ & - & - \\
\hline
\end{tabular}

the cohort according to specialization is provided in Table 2.

\section{Workload and psychosocial burden}

From July to September 2020, 83/154 participants (54\%) reported to have experienced shortages of personal protective equipment (PPE) at their department, of whom $46 \%(38 / 83)$ specified that these periods exceeded 4 weeks. Shortages in staffing since the onset of the SARS-CoV-2 pandemic were reported by $86 / 154(56 \%)$ respondents. About half of the participants $(80 / 154 ; 52 \%)$ reported sick leave rates at less than $10 \%, 34 / 154(22 \%)$ at $10-20 \%$ and $11 / 154$ (7\%) at $20-30 \%$, whereas 3 participants $(2 \%)$ reported substantially elevated rates at $30-40 \%$. A sick leave rate of $0 \%$ was only reported by 4 participants (3\%). Twenty-two participants (14\%) did not answered the question. Shortages concerning drug supplies were mentioned by $48 / 154$ (31\%) participants, as well as shortages in sterile goods (e.g., surgical instruments,
Table 3 Survey replies concerning the resumption of routine practice and elective surgery $(n=154)$

\begin{tabular}{|c|c|c|}
\hline & $(n)$ & $\%$ \\
\hline \multicolumn{3}{|c|}{ Resumed routine practice (including intensive care units) } \\
\hline Yes & 110 & 71 \\
\hline No & 38 & 25 \\
\hline "I don't know" & 6 & 4 \\
\hline \multicolumn{3}{|c|}{ Rate of postponed elective procedures (1 March-1 June 2020) } \\
\hline $0-\leq 20 \%$ & 15 & 10 \\
\hline$>20-\leq 40 \%$ & 23 & 15 \\
\hline$>40-\leq 60 \%$ & 38 & 25 \\
\hline$>60-\leq 80 \%$ & 47 & 30 \\
\hline$>80-\leq 100 \%$ & 19 & 12 \\
\hline "I don't know" & 12 & 8 \\
\hline \multicolumn{3}{|l|}{ Time period before resuming elective surgery } \\
\hline $\begin{array}{l}\text { Since the outbreak of the pandemic, elective } \\
\text { surgery has been performed in our depart- } \\
\text { ment without restrictions }\end{array}$ & 2 & 1 \\
\hline$<3$ weeks & 1 & $<1$ \\
\hline $3-6$ weeks & 46 & 30 \\
\hline $7-10$ weeks & 60 & 39 \\
\hline$>10$ weeks & 38 & 25 \\
\hline No elective surgeries are currently performed & 1 & $<1$ \\
\hline No answer & 1 & $<1$ \\
\hline Other ${ }^{\mathrm{a}}$ & 5 & 3 \\
\hline \multicolumn{3}{|c|}{$\begin{array}{l}\text { Did you have a SARS-CoV-2 outbreak at your surgical ward after resuming } \\
\text { elective surgeries? }\end{array}$} \\
\hline Yes & 7 & 5 \\
\hline No answer & 8 & 5 \\
\hline
\end{tabular}

wound care supplies, surgical gloves) by 50/154 (32\%) of participants.

Compared to routine practice before the pandemic, $47 / 154$ respondents (30\%) reported estimated the decrease of elective procedures at $60-80 \%$ between 1 March 2020 and 1 June 2020, and 25\% (38/154) estimated the decrease at $40-60 \%$ for elective procedures during this period. At the time of the survey (July to September 2020), most participants (110/154; $71 \%)$ reported that their hospital had resumed routine surgical practice, also including intensive care units. Seven respondents (5\%) alluded to an outbreak of SARS-CoV-2 after resuming elective procedures at their surgical department (Table 3).

Work-related dissatisfaction was reported to exist by $24 \%$ of all participants (33/138) already before the onset of the pandemic, which increased to $36 \%$ (50/138) after the first wave of infections in Germany. In more detail, work-related dissatisfaction was reported by $30 \%(14 / 47)$ of responding residents and $21 \%(19 / 91)$ of board-certified surgeons and anesthesiologists as prevalent already before the pandemic, increasing to $40 \%(19 / 47)$ among responding residents and to $34 \%(31 / 91)$ for board certified surgeons and anesthesiologists, following the first wave. The 
Table 4 Survey replies concerning associated factors for work-related dissatisfaction $(n=138)$

\begin{tabular}{|c|c|c|c|c|c|c|}
\hline & Strongly disagree & Somewhat disagree & Neither & Somewhat agree & Strongly agree & No answer \\
\hline \multirow[t]{2}{*}{ I feel threatened by the COVID-19 pandemic } & 26 & 33 & 23 & 48 & 6 & 2 \\
\hline & (19\%) & $(24 \%)$ & $(17 \%)$ & $(35 \%)$ & $(4 \%)$ & $(1 \%)$ \\
\hline \multirow{2}{*}{$\begin{array}{l}\text { Patient care has deteriorated due to the COVID } 19 \\
\text { pandemic }\end{array}$} & 14 & 36 & 23 & 39 & 24 & 2 \\
\hline & $(10 \%)$ & $(26 \%)$ & $(17 \%)$ & $(28 \%)$ & $(17 \%)$ & $(1 \%)$ \\
\hline \multirow{2}{*}{$\begin{array}{l}\text { I feel comfortable caring for patients despite the } \\
\text { current situation }\end{array}$} & 2 & 13 & 10 & 68 & 44 & 1 \\
\hline & $(1 \%)$ & $(10 \%)$ & $(7 \%)$ & $(49 \%)$ & $(32 \%)$ & $(<1 \%)$ \\
\hline \multirow{2}{*}{$\begin{array}{l}\text { I have an extensive knowledge of COVID-19, so } \\
\text { I am able to provide adequate care for patients }\end{array}$} & 5 & 21 & 32 & 60 & 18 & 2 \\
\hline & $(4 \%)$ & $(15 \%)$ & $(23 \%)$ & $(43 \%)$ & $(13 \%)$ & $(1 \%)$ \\
\hline \multirow{2}{*}{$\begin{array}{l}\text { Because elective surgeries are cancelled or post- } \\
\text { poned during the pandemic my workload has } \\
\text { increased }\end{array}$} & 7 & 24 & 22 & 56 & 27 & 2 \\
\hline & $(5 \%)$ & $(17 \%)$ & $(16 \%)$ & $(41 \%)$ & $(20 \%)$ & $(1 \%)$ \\
\hline \multirow{2}{*}{$\begin{array}{l}\text { The COVID-19 pandemic has caused traumatic } \\
\text { events in my professional work }\end{array}$} & 70 & 37 & 18 & 8 & 3 & 2 \\
\hline & $(51 \%)$ & $(27 \%)$ & $(13 \%)$ & $(6 \%)$ & (2\%) & (1\%) \\
\hline \multirow{2}{*}{$\begin{array}{l}\text { There are now more conflicts with colleagues } \\
\text { and/or superiors }\end{array}$} & 27 & 47 & 30 & 21 & 13 & \multirow[t]{2}{*}{-} \\
\hline & $(20 \%)$ & (34\%) & $(22 \%)$ & $(15 \%)$ & $(9 \%)$ & \\
\hline
\end{tabular}

workload before the SARS-CoV-2 pandemic was rated as high by $86 \%(119 / 138)$ of participants, whereas only $72 \%(99 / 138)$ still rated their personal workload as high at the time of the survey. A daily workload rated as excessive was reported by $19 \%(26 / 138)$ of participants before the pandemic, which decreased to $12 \%(16 / 138)$ at the time of the survey (Fig. 2).

Concerning stress factors potentially impacting professional dissatisfaction, a perception of threat by COVID-19 was indicated by 54/138 participants (39\%). A deterioration in patient care as an additional relevant factor was mentioned by 63/138 participants (46\%). Other factors potentially associated with increased professional dissatisfaction are provided in Table 4.

Further common stress factors related to the pandemic included increased worries about family and relatives 92/138 (67\%), worries about the own health status 51/138 (37\%), information overload 71/138
(51\%) and the requirement for acquisition of new knowledge and skills within a short time 60/138 (44\%) (Fig. 3).

To analyze whether answers on the questionnaire were correlated, Spearman's rank correlation coefficient $\rho$ was calculated for the ordinally scaled datasets. Here it was found that a sense of high workload and traumatic events due to the pandemic were associated with the most negative perceptions regarding work (Fig. 4).

The indication of work overload was significantly correlated with work dissatisfaction $(\rho=0.38)$, worries for relatives $(\rho=0.23)$, feeling the necessity to learn many new things in a short period of time $(\rho=0.17)$ as well as feeling threatened by the pandemic $(\rho=0.25)$. On the other hand, there was a significant negative correlation with the report of work overload and the feeling of providing good care to patients $(\rho=-0.42)$ and feeling well-informed about COVID-19 $(\rho=-0.24)$.

Table 5 Survey replies concerning the evaluation of mitigation strategies $(n=138)$

\begin{tabular}{|c|c|c|c|c|}
\hline & Not useful & Somewhat useful & Useful & No answer \\
\hline \multirow[t]{2}{*}{ Return to prepandemic conditions } & 81 & 26 & 28 & 3 \\
\hline & $(59 \%)$ & $(19 \%)$ & $(20 \%)$ & $(2 \%)$ \\
\hline \multirow{2}{*}{$\begin{array}{l}\text { Establishment of action plans to increase pandemic preparedness and to } \\
\text { strengthen public health systems }\end{array}$} & \multirow[t]{2}{*}{-} & 6 & 129 & 3 \\
\hline & & $(4 \%)$ & $(94 \%)$ & $(2 \%)$ \\
\hline \multirow{2}{*}{$\begin{array}{l}\text { Research of new approaches to better protect medical and nursing staff } \\
\text { from risks in pandemics }\end{array}$} & 2 & 8 & 127 & 1 \\
\hline & $(1 \%)$ & $(6 \%)$ & $(92 \%)$ & $(<1 \%)$ \\
\hline \multirow[t]{2}{*}{ Preparation of national guidelines for action to combat the pandemic } & 2 & 8 & 127 & 1 \\
\hline & $(1 \%)$ & $(6 \%)$ & $(92 \%)$ & $(<1 \%)$ \\
\hline \multirow[t]{2}{*}{ Preparation of regional and local action plans to combat the pandemic } & 7 & 12 & 118 & 1 \\
\hline & $(5 \%)$ & $(9 \%)$ & $(85 \%)$ & $(<1 \%)$ \\
\hline \multirow{2}{*}{$\begin{array}{l}\text { Establishment of concepts for more efficient personnel deployment in times } \\
\text { of crisis }\end{array}$} & 6 & 15 & 115 & 2 \\
\hline & $(4 \%)$ & $(11 \%)$ & $(83 \%)$ & $(1 \%)$ \\
\hline \multirow{2}{*}{$\begin{array}{l}\text { Extension of inter-professional cooperation and communication with other } \\
\text { fields }\end{array}$} & 5 & 20 & 111 & 2 \\
\hline & $(4 \%)$ & $(15 \%)$ & $(80 \%)$ & $(1 \%)$ \\
\hline \multirow[t]{2}{*}{ Prioritized testing of healthcare workers in the case of a pandemic } & 6 & 17 & 114 & 1 \\
\hline & $(4 \%)$ & $(12 \%)$ & $(83 \%)$ & $(<1 \%)$ \\
\hline
\end{tabular}


Work-related dissatisfaction

Worries about family and relatives

Worries about own health

Feeling of information overload

Acquisition of new knowledge \& skills within short time

I feel threatened by the pandemic

I feel comfortable caring for patients despite the current situation

I have an extensive knowledge of COVID-19

Because elective surgeries are cancelled or postponed my workload has increased

The pandemic has caused traumatic events in my professional work.

\begin{tabular}{|c|c} 
& \\
& 0 \\
& -0 \\
& -0 \\
& \\
& -0 \\
& \\
& \\
\hline ork. & $\mathbf{0}$ \\
\hline & 0,24 \\
\hline &
\end{tabular}

\begin{tabular}{|c|c|c|c|c|c|c|c|c|c|}
\hline & & & & & & & & & \\
\hline 11 & $\mathbf{0 , 3 0}$ & & & & & & & & \\
\hline & 0,00 & 0,13 & & & & & & & \\
\hline 0.20 & 0,17 & 0,31 & 0,11 & & & & & & \\
\hline & -0.36 & 0,42 & 0,29 & 0,20 & & & & & \\
\hline 0,33 & & 0,03 & 0,48 & $-0,10$ & $-0,16$ & & & & \\
\hline & $-0,20$ & 0,22 & 0,16 & 0,20 & 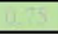 & 0,22 & & & \\
\hline 0,38 & 0,23 & 0,25 & & $\mathbf{0 , 1 7}$ & 0,25 & $-0,42$ & $-0,24$ & & \\
\hline 0,24 & 0,24 & 0,33 & $-0,12$ & & 0,22 & -0.21 & 0,11 & 0,38 & \\
\hline 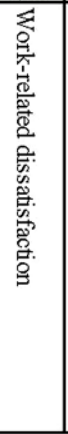 & 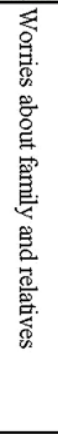 & 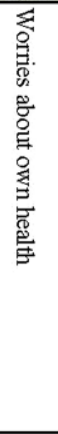 & 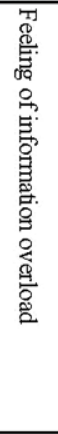 & 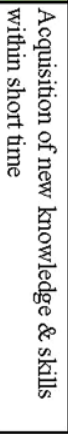 & 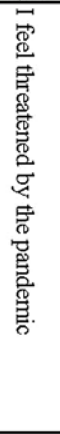 & 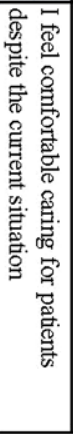 & 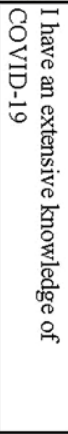 & 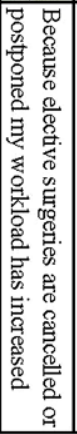 & 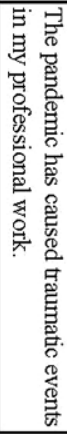 \\
\hline
\end{tabular}

Fig. 4 Correlation analysis of survey replies concerning different stress factors. The correlation matrix displays the statistical relation of answers on the questionnaire as Spearman's rank correlation coefficient. Statistically significant results are printed in bold, non-significant results are grayed out. A correlation coefficient is usually considered to indicate a negligible correlation from 0.00 to \pm 0.19 , a weak correlation from \pm 0.20 to \pm 0.39 , a moderate correlation from \pm 0.40 to \pm 0.59 , a strong correlation from \pm 0.60 to \pm 0.79 , and a very strong correlation from \pm 0.80 to \pm 1.00 . A positive correlation coefficient indicates a positive relationship between the two variables, while a negative correlation coefficient indicates a negative relationship
Reporting traumatic events due to the pandemic was significantly correlated with work dissatisfaction $(\rho=0.24)$ and work overload $(\rho=0.38)$, worries for relatives $(\rho=0.24)$ and for one's own health $(\rho=0.33)$ as well as the perception of being threatened by the pandemic $(\rho=0.22)$. Although all of these findings were formally significant, it should be duly noted that single correlations remained weak to moderate throughout and therefore require context for sensible interpretation.

\section{Mitigation strategies for future challenges}

For an improved management of prevalent shortfalls caused by the pandemic as well as the encountered challenges, various predefined measures were to be rated as potentially useful by the survey participants. Most respondents (129/138; 94\%) agreed that action plans to increase pandemic preparedness and for strengthening public health systems are useful and important countermeasures. Also, additional research into novel approaches to increase protection of healthcare workers from SARS-CoV-2-related health risks was mentioned as a sensible measure by the vast majority of participants (127/138; 92\%). According to most participants in the survey, national $(127 / 138 ; 92 \%)$ as well as regional $(118 / 138 ; 85 \%)$ guidelines to counteract an outbreak in the context of epidemic infectious diseases should be established. Establishment of concepts for more efficient staff de- ployment during crises was also rated as useful by $115 / 138$ (83\%) of the respondents. Strengthening interprofessional cooperation and communication was frequently deemed as a helpful measure $(80 \%)$ as well as prioritized diagnostic testing for healthcare personnel during a pandemic $(83 \%)$, whereas a hastened return to prepandemic conditions was rejected by $59 \%$ of survey respondents (Table 5).

\section{Discussion}

The aftermath of the first and subsequent waves of SARS-CoV-2 infections has burdened the surgical and anesthesiologic staff in Germany. Our survey attests that elective surgery was relevantly impacted by postponed or cancelled procedures to minimize the risk of perioperative SARS-CoV-2 infection and to free up healthcare resources. A key challenge of the pandemic were staff shortages, as frequently mentioned by participating physicians. Furthermore, stress perceived through impaired patient care and/or the feeling of anxiety by the SARS-CoV-2 pandemic may be associated with the increased work-related dissatisfaction identified. Increased worries about family and relatives may be considered another main stress factor, adding to the psychosocial burden of healthcare staff. It seems important to review issues that have been encountered during the initial phase of the pandemic to enable the development of action plans for increasing 
pandemic preparedness and supporting public health systems.

The answers provided to our survey confirmed shortages in basic supplies such as the availability of PPE. Most surgeons and anesthesiologists reported witnessing a shortage of PPE within their department after the onset of the pandemic. Comparable results were reported by Brunner et al. who reported a lack of PPE in $45 \%$ of 101 participating German hospitals [15]. Furthermore, a survey conducted by the Royal College of Surgeons of England among 1978 surgeons revealed that one third of them lacked access to adequate PPE [16]. In a global online survey by Tabah et al. $52 \%$ of respondents indicated a lack of adequate access to at least one PPE item [17]. According to our survey, $54 \%$ of the participants experienced a lack of PPE, among whom $46 \%$ reported this shortage to last for at least 4 weeks. In an international study from 26 countries by Yanez Benitez et al. 54\% of surgeons responded that their work was impaired by the lack of PPE and $51 \%$ stated that they did not feel sufficiently protected by the PPE provided [18].

According to our survey, drug supply shortages were indicated by $31 \%$ and shortages in sterile goods by $32 \%$ of respondents. This circumstance appears critical for patient care, also when the strongly increased demand for certain essential drugs (e.g. sedatives) is taken into account [19]. Studies concerning shortages of staff and supplies were unavailable at the time of our study, leaving the final assessment of the international situation still open; however, more recently the COVIDSurg Collaborative has provided an international surgical workforce prediction model, addressing COVID-19 related absences in the surgical setting. During the initial 6 weeks of the global outbreak the COVID-19-related absence of surgeons ranged between $20.5 \%$ and $24.7 \%$, which corresponds well with the data from our survey [20].

Postponing and cancelling elective surgery was introduced in Germany on 16 March 2020 and has lasted to varying degrees over the following year, in order to reserve capacities on intensive care units for COVID19 patients and to reduce the perioperative risk for patients [13]. The restrictions in surgical capacity were substantial, especially during the first national lockdown lasting from 1 March to 1 June 2020. Our survey supports this, as $55 \%$ of respondents estimated the cancellation rate of elective surgery to range between $40 \%$ and $80 \%$ and $12 \%$ of respondents even estimated this to be higher than $80 \%$. This picture fits the international situation at the time, as, e.g. an international study in 54 countries reported a COVID19-related overall reduction of oral and maxillofacial surgery activities by $56 \%$ [21]. Respondents to a study from Johnson et al. alluded to a decrease of $90 \%$ for vascular surgeries in the USA [22] and in Austria, a complete cancellation of elective vascular surgery was reported by most of the 12 centers surveyed during the first surge of the pandemic [23]. Of note, $5 \%$ of respondents to our survey stated that they had become aware of a SARS-CoV-2 outbreak at their department after resuming elective procedures, leading to repeated cancellations of elective procedures. Anecdotally, such a phenomenon has been reported before, e.g. in a study from Wuhan, China, where two SARS-CoV-2 outbreaks were reported on a surgical ward involving both patients and healthcare workers [24], or likewise in a report from a hemodialysis unit in Canada [25]. A premature return to regular elective surgery without appropriately adapted mitigation measures therefore involves a relevant risk of infection outbreaks. To lower the risk of nosocomial infections, COVID-19-free pathways for elective surgery have been proposed and were linked to a positive impact when aiming to protect vulnerable patients [26] as well as vaccinations before elective surgery [27]. Systematic PCR testing of patients before surgical procedures has also been proven as a useful tool for preventing COVID-19-related complications [28].

The SARS-CoV-2 pandemic has also relevantly affected the personal lives of physicians. According to the survey data, most respondents stated that worries concerning family and relatives have significantly increased, contributing additional stressors. This notion is supported by a study from Collins et al. where worries for immediate family members were identified as one of the main stress factors during the current pandemic [29]. Furthermore, Tan et al. [30] proposed that longitudinal mental support should be made accessible to healthcare workers in exceptional situations, such as a pandemic, a view which may generally be supported by our results attesting to a negative impact of (traumatic) events during the pandemic on worklife balance. For future public health crises, this could be considered when developing measures to support healthcare workers. Immediate measures might therefore also include close family of healthcare professionals.

The presented study findings are limited by the small sample size, which may reduce the generalizability and question the validity of findings across Germany and different hospital settings. Another limitation is a primary study focus on the subjectively perceived stress factors among the study participants as well as asking for events in the past. Due to this fact, recall bias as a potential methodological issue influencing the results cannot be excluded. This survey, however, was not planned as a longitudinal study with repeat questionnaires, therefore such changes cannot be addressed over time.

This present study is one of the very few studies conducted in Germany that comprehensively addressed psychosocial stressors as well as mitigation measures after the first peak of the SARS-CoV-2 pandemic. A major strength of our study is the coverage of various challenges at different levels (occupational, personal, co-environmental). Furthermore, besides the assessment of psychosocial burden, measures at 
the level of the public health system were queried, representing a prerequisite to identify relevant problem areas when searching for potential solutions.

Acknowledgements The authors would like to thank all the survey participants who volunteered and provided their time and information to us.

Funding Open Access funding enabled and organized by Projekt DEAL.

Conflict of interest A. Grishina, F. Link, A. Arend, F. Kleemann, P. Tober-Lau, D. Andree, F. Münn, M. Gruendl, M. Quante, H. Lederhuber, M. Albertsmeier, F. Struller, R. Grützmann, A. Königsrainer and M.W. Löffler declare that they have disclosed all potential financial conflicts of interest that might be regarded as possibly influencing the results or interpretation of the manuscript and declare no potential conflicts of interest.

Open Access This article is licensed under a Creative Commons Attribution 4.0 International License, which permits use, sharing, adaptation, distribution and reproduction in any medium or format, as long as you give appropriate credit to the original author(s) and the source, provide a link to the Creative Commons licence, and indicate if changes were made. The images or other third party material in this article are included in the article's Creative Commons licence, unless indicated otherwise in a credit line to the material. If material is not included in the article's Creative Commons licence and your intended use is not permitted by statutory regulation or exceeds the permitted use, you will need to obtain permission directly from the copyright holder. To view a copy of this licence, visit http://creativecommons.org/licenses/by/4.0/.

\section{References}

1. Muller AE, et al. The mental health impact of the covid19 pandemic on healthcare workers, and interventions to help them: a rapid systematic review. Psychiatry Res. 2020;293:113441. https://doi.org/10.1016/j.psychres. 2020.113441

2. Pappa S, et al. Prevalence of depression, anxiety, and insomnia among healthcare workers during the COVID-19 pandemic: a systematic review and meta-analysis. Brain Behav Immun. 2020;88:901-7. https://doi.org/10.1016/j. bbi.2020.05.026

3. Kramer V, et al. Subjective burden and perspectives of German healthcare workers during the COVID-19 pandemic. Eur Arch Psychiatry Clin Neurosci. 2021;271(2):271-81. https://doi.org/10.1007/s00406-020-01183-2

4. Nguyen LH, et al. Risk of COVID-19 among front-line health-careworkers and thegeneral community: aprospective cohort study. Lancet Public Health. 2020;5(9):e475-83. https://doi.org/10.1016/S2468-2667(20)30164-X

5. Liu Q, et al. The experiences of health-care providers during the COVID-19 crisis in China: a qualitative study. Lancet Glob Health. 2020;8(6):e790-8. https://doi.org/10.1016/ S2214-109X(20)30204-7

6. Robert Koch Institute (RKI). Daily situation report of the Robert Koch institute. Robert Koch Institute (RKI): RKI; 2020. Updated status: 31 May 2020.

7. Mehta S, et al. COVID-19: a heavy toll on health-care workers. Lancet Respir Med. 2021;9(3):226-8. https://doi. org/10.1016/S2213-2600(21)00068-0

8. Eftekhar Ardebili M, et al. Healthcare providers experience of working during the COVID-19 pandemic: a qualitative study. Am J Infect Control. 2021;49(5):547-54. https://doi. org/10.1016/j.ajic.2020.10.001

9. Kambhampati AK, O'Halloran AC, Whitaker M. COVID19-associated hospitalizations among health care personnel-COVID-NET, 13 states, March 1-May 31. MMWR Morb Mortal Wkly Rep. 2020;69:1576-83. https://doi.org/ 10.15585/mmwr.mm6943e3

10. COVIDSurg Collaborative. Mortality and pulmonary complications in patients undergoing surgery with perioperative SARS-CoV-2 infection: an international cohort study. Lancet. 2020;396(10243):27-38. https://doi.org/10.1016/ S0140-6736(20)31182-X

11. Aminian A, et al. COVID-19 outbreak and surgical practice: unexpected fatality in perioperative period. Ann Surg. 2020;272(1):e27-9. https://doi.org/10.1097/SLA. 0000000000003925

12. Mouton C, et al. COVID-19-ESSKA guidelines and recommendations for resuming elective surgery. J Exp Ortop. 2020;7(1):28. https://doi.org/10.1186/s40634-020-00248-

13. COVIDSurg Collaborative. Elective surgery cancellations due to the COVID-19 pandemic: global predictive modelling to inform surgical recovery plans. $\mathrm{Br} \mathrm{J}$ Surg. 2020;107(11):1440-1449. https://doi.org/10.1002/ bjs. 11746

14. Stöß C, et al. The COVID-19 pandemic: impact on surgical departments of non-university hospitals. BMC Surg. 2020;20(1):313. https://doi.org/10.1186/s12893020-00970-X

15. Brunner $\mathrm{M}$, et al. Oncological colorectal surgery during the COVID-19pandemic - a national survey. Int J Colorectal Dis. 2020;35(12):2219-25. https://doi.org/10.1007/ s00384-020-03697-6

16. Jessop ZM, et al. Personal protective equipment (PPE) for surgeons during COVID-19 pandemic: a systematic review of availability, usage, and rationing. Br J Surg. 2020;107(13):e650. https://doi.org/10.1002/bjs.11980

17. Tabah A, et al. Personal protective equipment and intensive care unithealthcareworker safetyin theCOVID-19 era (PPESAFE): an international survey. J Crit Care. 2020;59:70-5. https://doi.org/10.1016/j.jcrc.2020.06.005

18. Yánez Benítez $C$, et al. Impact of personal protective equipment on surgical performance during the COVID-19 pandemic. World J Surg. 2020;44(9):2842-7. https://doi. org/10.1007/s00268-020-05648-2

19. Ayati N, Saiyarsarai P, Nikfar S. Short and long term impacts of COVID-19 on the pharmaceutical sector. DARU J Pharm Sci. 2020;28(2):799-805. https://doi.org/10.1007/s40199020-00358-5

20. COVIDSurg Collaborative. COVID-19-related absence among surgeons: development of an international surgical workforce prediction model. BJS Open. 2021;5(2):zraa021. https://doi.org/10.1093/bjsopen/zraa021

21. Maffia F, et al. Impact of COVID-19 on maxillofacial surgery practice: a worldwide survey. Int J Oral Maxillofac Surg. 2020;49(6):827-35. https://doi.org/10.1016/j.ijom.2020. 04.015

22. Johnson AP, et al. The impact of the COVID-19 pandemic on vascular surgery trainees in the United States. Ann Vasc Surg. 2020;72:182-190. https://doi.org/10.1016/j.avsg. 2020.09.045

23. Klocker J, et al. Operieren, Absagen, Verschieben oder Selektionieren? [Operate, cancel, postpone or select?] Gefässchirurgie. 2020;25:417-422. https://doi.org/10. 1007/s00772-020-00686-5

24. Gao S, et al. Two outbreaks of SARS-CoV-2 in department of surgery in a Wuhan hospital. Infect Prev Pract. 
2020;2(3):100065. https://doi.org/10.1016/j.infpip.2020 . 100065

25. Yau K, et al. COVID-19 outbreak in an urban hemodialysis unit. Am J Kidney Dis. 2020;76(5):690-695.el. https://doi. org/10.1053/j.ajkd.2020.07.001

26. COVIDSurg Collaborative. Elective cancer surgery in COVID-19-free surgical pathways during the SARS-coV-2 pandemic: an international, multicenter, comparative cohort study. J Clin Oncol. 2021;39(1):66-78. https://doi.org/ 10.1200/JCO.20.01933

27. COVIDSurg Collaborative \& GlobalSurg Collaborative. SARS-CoV-2 vaccination modelling for safe surgery to save lives: data from an international prospective cohort study. Br J Surg. 2021;108(9):1056-1063. https://doi.org/10.1093/ bjs/znab101
28. COVIDSurg Collaborative. Preoperative nasopharyngeal swab testing and postoperative pulmonary complications in patients undergoing elective surgery during the SARSCoV-2 pandemic. Br JSurg. 2020;108(1):88-96. https://doi. org/10.1093/bjs/znaa051

29. Collins C, etal. Stress and the surgical residentin the COVID19 pandemic. J Surg Educ. 2021;78(2):422-430. https:// doi. org/10.1016/j.jsurg.2020.07.031

30. Tan YQ, et al. Psychological health of surgeons in a time of COVID-19: a global survey. Ann Surg. 2021. https://doi. org/10.1097/SLA.0000000000004775

Publisher's Note Springer Nature remains neutral with regard to jurisdictional claims in published maps and institutional affiliations. 